\title{
Symptomatic fever management among 3 different groups of pediatricians in Northern Lombardy (Italy): results of an explorative cross-sectional survey
}

Alberto Bettinelli ${ }^{1 *}$, Maria Cristina Provero ${ }^{1,2}$, Felice Cogliati ${ }^{1}$, Anna Villella ${ }^{3}$, Maddalena Marinoni ${ }^{2}$, Francesco Saettini ${ }^{4}$, Mario Giovanni Bianchetti ${ }^{5}$, Luigi Nespoli ${ }^{2}$, Cino Galluzzo ${ }^{6}$ and Sebastiano Antonio Giovanni Lava ${ }^{5}$

\begin{abstract}
Background: In the care of feverish children, symptomatic management is pivotal. Thus, the Italian Pediatric Society has recently published guidelines on fever management in children. Our aim was to investigate whether pediatric hospitalists, community pediatricians and pediatric residents differ in their every-day clinical practice with respect to symptomatic management of feverish children.

Methods: 79 out of 118 physicians involved in pediatric care in an area of Northern Lombardy (Italy) filled in a modified version of the questionnaire derived from the Swiss national survey on symptomatic fever management.

Results: Pediatric hospitalists ( $N=29)$, community pediatricians $(N=30)$ and pediatric residents $(N=20)$ did not differ with respect to temperature threshold for symptomatic fever treatment, role of general appearance in modulating the threshold for fever management, first choice antipyretic drug, frequency of ibuprofen prescription, prescription of physical antipyresis, influence of exaggerated fear of fever on its management and potential to reassure families about this fear.

On the other side, some significant differences were found. Pediatric residents more frequently lower the treatment threshold in children with a past history of febrile seizures $(P<0.001)$ and prescribe an aggressive treatment for fever not responding to the first antipyretic drug $(P<0.01)$ than their more experienced colleagues. Community pediatricians represent the unique investigated group using homeopathic remedies, both in the acute setting $(P<0.001)$ as well as a prophylaxis $(P<0.0001)$. Finally, paediatric residents less often $(P<0.05)$ stated to encounter exaggerated fear of fever among parents than their more experienced colleagues.
\end{abstract}

Conclusions: The present explorative inquiry globally shows limited discordance among pediatric residents, community pediatricians and pediatric hospitalists with respect to symptomatic fever management.

Keywords: Fever, Pediatrician attitudes, Acetaminophen (paracetamol), Ibuprofen

\footnotetext{
* Correspondence: a.bet@libero.it

'Department of Pediatrics, San Leopoldo Mandic Hospital, Merate, Italy

Full list of author information is available at the end of the article
} 


\section{Background}

Since symptomatic management of fever is crucial both in self-limiting (mostly viral) and in severe (mostly bacterial) febrile illnesses [1,2], the Italian Pediatric Society has recently published guidelines on fever management in children $[3,4]$.

Interestingly, some differences in diagnostic and therapeutic patterns among pediatric hospitalists, community pediatricians and paediatric residents have been observed $[5,6]$. Our aim was to investigate whether pediatric hospitalists, community pediatricians and pediatric residents differ in their every-day clinical practice with respect to the adherence to available guidelines on fever management.

\section{Methods}

Between June and September 2012, we invited some of the physicians involved in pediatric care in the Provinces of Lecco, Como and Varese (Northern Lombardy, Italy) to fill in a questionnaire dealing with symptomatic management of fever. For this purpose, we slightly modified the close-ended questionnaire developed for the Swiss national survey on symptomatic fever management $[7,8]$. The 118 invited physicians included 29 pediatric residents, 48 community pediatricians and 41 pediatric hospitalists. While pediatric hospitalists worked at 4 different hospitals, pediatric residents all worked at the same institution.

To identify potential differences among the 3 groups of physicians, we analyzed the answers to 12 written questions that elicit information about the following: (1) rectal temperature threshold for initiating pharmacologic management of fever in a 3-year-old child who appears comfortable (possible answers: $<38.0^{\circ} \mathrm{C}, 38.0-38.4^{\circ} \mathrm{C}$, $38.5-38.9^{\circ} \mathrm{C}, 39.0-39.4^{\circ} \mathrm{C}$, or $\geq 39.5^{\circ} \mathrm{C}$ ); (2) the importance of a child's general appearance in choosing the temperature threshold for initiating pharmacologic treatment of fever (never or rarely, sometimes, or often important); (3) the value of a child's history of febrile seizures in choosing the temperature threshold for initiating pharmacologic treatment of fever (never or rarely, sometimes, or often important); (4) the prescribing of acetaminophen (paracetamol) as the first choice drug in the management of fever (first choice or not first choice); (5) the prescribing of oral ibuprofen for fever (never or rarely, sometimes, or often prescribed); (6) the management of a comfortable child with fever that is nonresponsive to an antipyretic drug (wait and see, replace the initial drug with a new one, or add a second drug to the first one); (7) the prescribing of physical methods of antipyresis (never or rarely, sometimes, or often prescribed); (8) the prescription of homeopathic remedies for the acute management of fever (yes or no) or for (9) its prevention (yes or no); (10) the perceived frequency of an exaggerated fear of fever among parents (never or rarely, sometimes, or often present); (11) the influence of exaggerated fear of fever on the drug management of fever (never or rarely, sometimes, or often lower threshold because of parental worries); and (12) the possibility of educating families about the fear of fever (never or rarely, sometimes, or often possible).

Ordered categorical responses to the questionnaire were assigned a numerical score. Numerical data were analyzed using the Kruskal-Wallis test and the Bonferroni-Dunn post hoc procedure. The Fisher exact test was used to analyze proportions. Significance was assigned at $\mathrm{P}<0.05$ (two-tailed).

\section{Results}

Seventy-nine (67\%) out of the 118 invited physicians answered the questionnaire (Table 1). The rectal temperature threshold for symptomatic fever treatment was similar in the three study groups [Figure 1, upper panel]. Furthermore, $\geq 45 \%$ of the participants never or rarely lower the treatment threshold in front of a febrile child who is presenting with a reduced general appearance, without any difference between the 3 groups [Figure 1, middle panel]. Finally, in all groups $\geq 54 \%$ of the participants often reduce the temperature threshold for initiating an antipyretic treatment in children with a past history of febrile seizures [Figure 1, lower panel]. This attitude is more frequent $(\mathrm{P}<$ 0.001 ) among pediatric residents (100\%) than among pediatric hospitalists (54\%), without any significant difference between community pediatricians (77\%) and the other two groups.

In all groups, $\geq 97 \%$ of the participants prescribe acetaminophen as the first choice antipyretic drug (no significant difference was noted between the 3 groups) [Figure 2, upper panel]. Ibuprofen is sometimes or often used by $\geq 67 \%$ of physicians in each of the investigated categories, with $33 \%$ or less using it only rarely [Figure 2, middle panel]. No significant differences were found among the 3 groups. The management of a comfortable child whose fever does not respond to the first antipyretic drug differs among groups: pediatric residents replace the first drug with another antipyretic $(50 \%)$ or, more rarely, add a second drug to the existing regimen (20\%) more frequently than community pediatricians $(20 \%$ and $3 \%$, respectively; $\mathrm{P}<0.01)$ and pediatric hospitalists $(10 \%$ and $7 \%$, respectively; $\mathrm{P}<0.001)$ [Figure 2, lower panel].

In all groups, physical methods of antipyresis are used at least sometimes by $\geq 59 \%$ of the participants, without significant differences between groups [Figure 3, upper panel]. Hospitalists and residents never prescribe homeopathic remedies [Figure 3, middle and lower panel]. On the contrary, community pediatricians sometimes prescribe homeopathy both in the acute setting $(17 \%$; $\mathrm{P}<$ $0.001)$ as well as prophylaxis $(38 \%$; $\mathrm{P}<0.0001)$. 
Table 1 Number of invited and respondent participants and their gender in the 3 groups of pediatricians ( $M$ : $F$ ratio $=$ male-to-female ratio)

\begin{tabular}{lcccc}
\hline & Total number of participants & Pediatric residents & Community pediatricians & Pediatric hospitalists \\
\hline $\begin{array}{l}\text { Respondents/Invited } \\
\text { (percentage of respondents) }\end{array}$ & $79 / 118(67 \%)$ & $20 / 29(69 \%)$ & $30 / 48(60 \%)$ & $29 / 41(71 \%)$ \\
Respondents, M : F ratio & $16: 63$ & $3: 17$ & $7: 23$ & $6: 23$ \\
\hline
\end{tabular}

Participants from all the 3 groups consider that exaggerated fear of fever is frequent among parents. Nevertheless, the stated occurrence [Figure 4, upper panel] is lower $(\mathrm{P}<0.05)$ among pediatric residents $(50 \%$ of the participants state that fear of fever is frequent) than among community pediatricians $(63 \%)$ and pediatric hospitalists $(90 \%)$, with no significant difference between the latter two groups. In all groups $\geq 63 \%$ of the participants state that they rarely or never lower the temperature threshold [Figure 4, middle panel] for initiating a treatment in order to calm worried parents (without

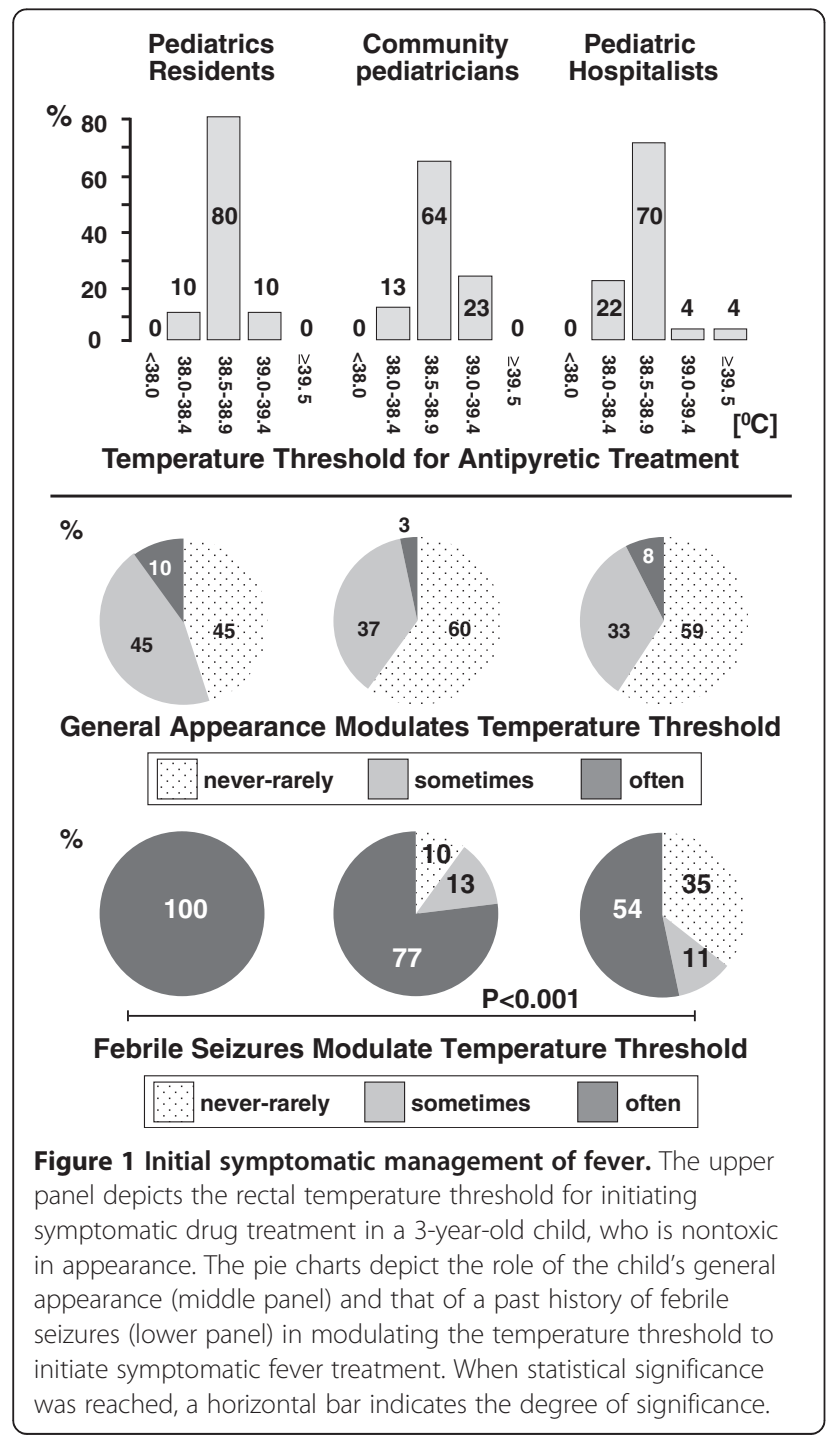

significant difference between the 3 groups). Similarly, in all groups, $\geq 86 \%$ of the participants consider that it is sometimes or often possible to educate and reassure families [Figure 4, lower panel] about the fear of fever (without significant differences between the 3 groups).

\section{Discussion}

The present explorative inquiry globally shows limited discordance among the 3 groups of investigated pediatricians,

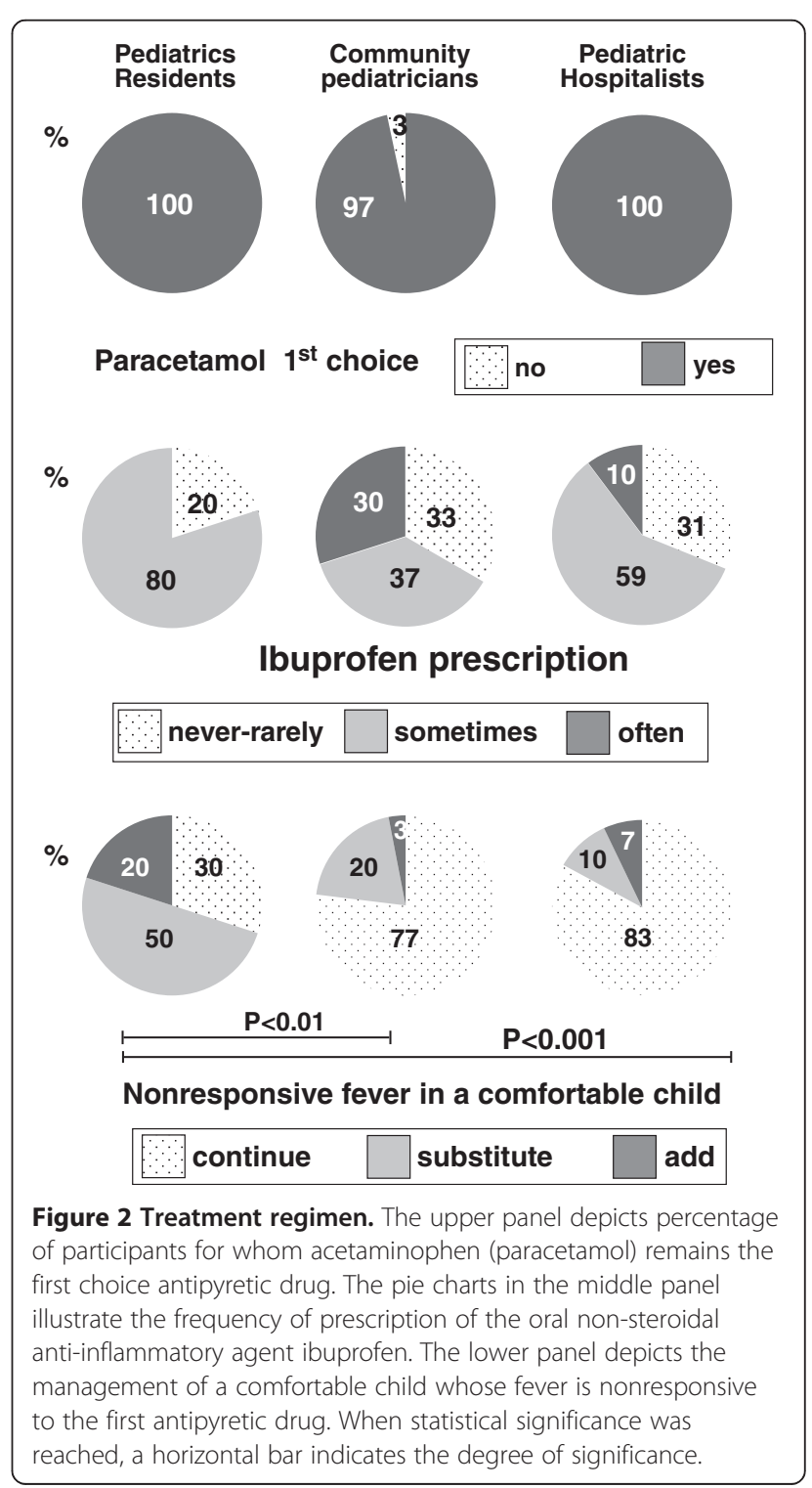




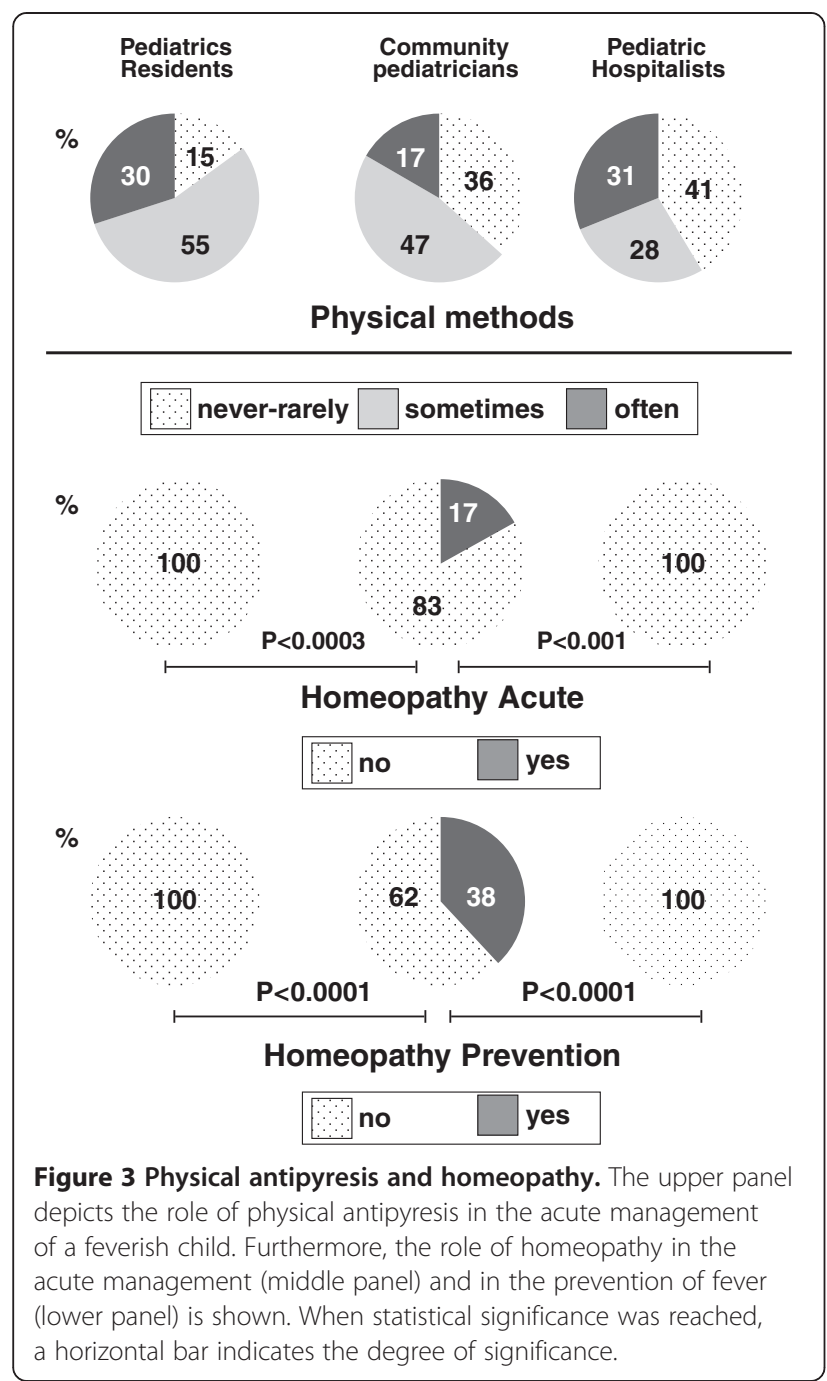

with only 5 issues reaching a statistically significant difference, as depicted in Table 2.

First, the rectal temperature threshold for symptomatic fever treatment was similar $\left(38.5^{\circ}-39.0^{\circ}\right)$ to that reported in a recent Italian study performed among pediatricians [9]. Second, it is currently advised that antipyretic drugs should be prescribed only when fever is associated with evident discomfort [3,4,10-13]. The present survey indicates that the child's general appearance only rarely modulates the threshold for symptomatic fever treatment throughout the analyzed groups of pediatricians. Third, antipyretics are not effective in preventing febrile seizures and should therefore be avoided [3,4,10-15]. According to our results, more experienced hospital-based pediatricians less frequently differ from this recommendation than their younger colleagues.

Fourth, in all interviewed groups, $\geq 97 \%$ of the participants stated to prescribe acetaminophen as the first choice antipyretic. The fact that ibuprofen is sometimes

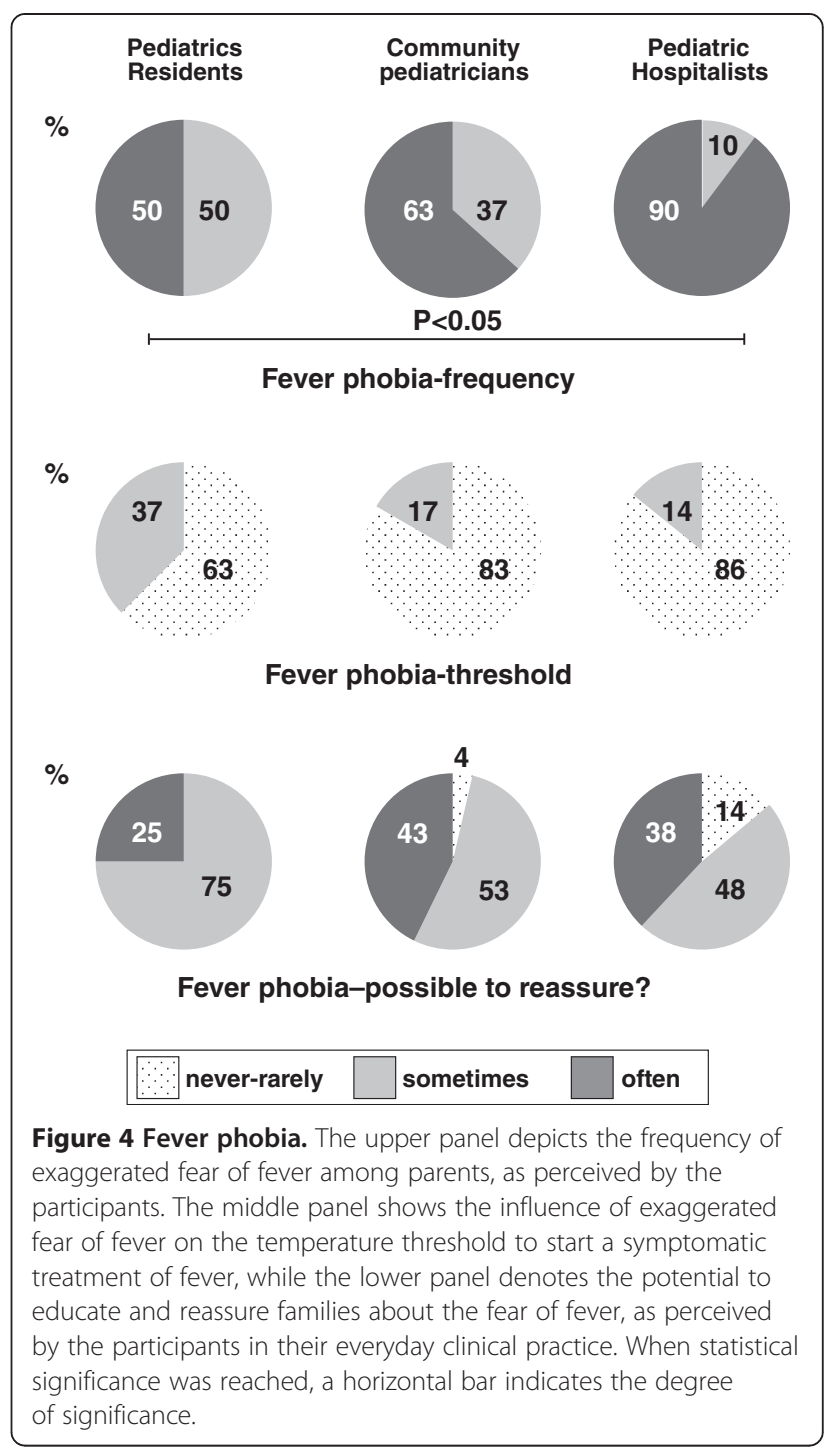

or often used by $\geq 67 \%$ of participants indicates that this non-steroidal agent is often used as an alternative to acetaminophen. Both results reflect the attitudes of Italian Pediatricians reported in a recently published survey [9]. Fever not responding to a first antipyretic agent does not signalize the presence of a serious or dangerous illness [16]. However, high temperature that does not go down may be associated with a suffering and uncomfortable child and should therefore be effectively managed $[3,4,7,8,10-12]$. Therefore, in our survey we explicitly asked about the management of a nonresponsive fever in a comfortable child. As compared to pediatric hospitalists and community pediatricians, pediatric residents more often aggressively treat a comfortable child whose fever is not going down, either by replacing the first antipyretic drug or by adding a second agent. This attitude likely reflects greater worries about this condition. 
Table 2 Distinctivenesses in symptomatic fever management among pediatric residents, community pediatricians and pediatric hospitalists practising in an area of Northern Lombardy

\begin{tabular}{lccc}
\hline & Pediatric residents & Community pediatricians & Pediatric hospitalists \\
\hline Febrile seizures modulate temperature threshold & ++ & + & - \\
Aggressive treatment of nonresponsive fever in a comfortable child & + & + \\
Homeopathy in the acute setting & - & + \\
Homeopathy as prophylaxis & + & ++ \\
Exaggerated fear of fever frequent & & - \\
\hline The symbol ++ means very common, the symbol + frequent and the symbol - rare. & ++ \\
\hline
\end{tabular}

Sixth, physical methods of antipyresis $[17,18]$ are used at least sometimes by $\geq 59 \%$ of the respondents throughout the analyzed groups. This roughly mirrors the results of a recent study performed in a larger sample of Italian Pediatricians [9], but does unfortunately not recflect the guideline recommendations $[3,4,7,8,11,13,15]$. Seventh, homeopathy is a controversial practice founded by the German physician Samuel Hahnemann in the late $18^{\text {th }}$ century [19]. In our sample, homeopathic remedies are prescribed exclusively by a minority of community pediatricians. This might reflect an attempt to reassure patients and caregivers by prescribing innocuous remedies with no proven effect beyond placebo.

The presence of several unrealistic fears about fever, firstly noted in 1980, has been called 'fever phobia' [20]. Since then, several studies have recognized its presence both among caregivers as well as health professionals [20-25]. Intriguingly, pediatric residents appear to encounter fever phobia less often than their more experienced hospital-based colleagues. This is surprising, since residents more often declared to use non-evidence based practices such as a more aggressive treatment of a nonresponsive fever or the "prophylactic" prescription of antipyretics for children with a history of febrile seizures (Table 2). Since the spectrum of patients cared for by residents, hospitalists and community-pediatricians is likely identical, it is tempting to assume that young residents tend to underrecognize fever phobia. Part of the reason for this tendency might reside in the fact that physicians themselves (and, we guess, residents maybe stronger than more experienced clinicians) can be victims of fever phobia [22,26,27].

Our results must be interpreted with an understanding of some methodological limitations. First, since a study based on a small number of participants has little chance of producing clear-cut conclusions, the results of our explorative survey with 3 small groups of residents, hospitalists and community-based pediatricians might deserve confirmation with a larger sample of participants. Second, the results of this study, performed in Northern Lombardy, cannot be automatically generalized to other regions of Italy or to other Countries. In fact, data comparing the mentioned 3 groups of physicians in other Countries are currently not yet available.
Third, although self-reported physicians' questionnaires have been frequently used, answers on surveys that ask doctors how they deal with specific conditions, sometimes differ from their everyday clinical practice [8]. Finally, the provided data are simply quantitative. The present survey did not investigate the reasons underlying the answers provided by the interviewed physicians. Thus, all the explanations are speculative. In order to analyze possible reasons explaining the differences in symptomatic fever management among the 3 study groups, a qualitative study based on in-depth interviews would be helpful.

In conclusion, this explorative study demonstrates limited discordance among pediatric residents, community pediatricians and pediatric hospitalists with respect to symptomatic fever management (Table 2). Larger confirmatory studies deserve to be performed.

\section{Competing interests}

The authors declare that they have no competing interests.

\section{Authors' contributions}

$A B$ and $S A G L$ designed the study, performed statistical analysis and wrote the initial draft. SAGL and MGB prepared the figures. MCP, FC, AV, MM, FS, LN and CN took the verbal consent, administered and collected the questionnaires. All authors read and approved the final manuscript.

\section{Author details}

'Department of Pediatrics, San Leopoldo Mandic Hospital, Merate, Italy. ${ }^{2}$ Department of Clinical and Experimental Medicine, Ospedale Pediatrico Filippo del Ponte, Varese, Italy. ${ }^{3}$ Community Pediatrician, Merate, Italy. ${ }^{4}$ Department of Pediatrics, San Gerardo Hospital, Monza, Italy. ${ }^{5}$ Department of Pediatrics, San Giovanni Hospital, Bellinzona and University of Bern, Bern, Switzerland. 'Department of Pediatrics, Fatebenefratelli Hospital, Erba, Como, Italy.

Received: 6 June 2013 Accepted: 27 August 2013

Published: 2 September 2013

\section{References}

1. National Institute for Health and Clinical Excellence: Feverish illness in children: assessment and initial management in children younger than 5 years. NICE: Guidance. London (UK): RCOG Press; 2007. May. 47.

2. Avner JR: Acute fever. Pediatr Rev 2009, 30:5-13.

3. Chiappini $E$, Principi $N$, Longhi $R$, Tovo PA, Becherucci $P$, Bonsignori $F$, Esposito S, Festini F, Galli L, Lucchesi B, Mugelli A, de Martino M, Writing Committee of the Italian Pediatric Society Panel for the Management of Fever in Children: Management of fever in children: summary of the Italian pediatric society guidelines. Clin Ther 2009, 31:1826-1843. 
4. Chiappini E, Venturini E, Principi $N$, Longhi $R$, Tovo PA, Becherucci $P$, Bonsignori F, Esposito S, Festini F, Galli L, Lucchesi B, Mugelli A, de Martino M, Writing Committee of the Italian Pediatric Society Panel for the Management of Fever in Children: Update of the 2009 Italian pediatric society guidelines about management of fever in children. Clin Ther 2012 34:1648-1653. e3.

5. Conway PH, Edwards S, Stucky ER, Chiang WW, Ottolini MC, Landrigan $C P$ : Variations in management of common inpatient pediatric illnesses: hospitalists and community pediatricians. Pediatrics 2006, 118:441-447.

6. Wells RD, Dahl B, Nilson B: Comparison of the levels of quality of inpatient care delivered by pediatrics residents and by private, community pediatricians at one hospital. Acad Med 1998, 73:192-197.

7. Lava SA, Simonetti GD, Ramelli GP, Tschumi S, Bianchetti MG: Symptomatic management of fever among Swiss board-certified pediatricians: the results of a cross-sectional web-based survey. Clin Ther 2012, 34:250-256.

8. Lava SA, Simonetti GD, Ferrarini A, Ramelli GP, Bianchetti MG: Regional differences in symptomatic fever management among paediatricians in Switzerland: the results of a cross-sectional web-based survey. $\mathrm{Br} J \mathrm{Clin}$ Pharmacol 2013, 75:236-243.

9. Chiappini E, Parretti A, Becherucci P, Pierattelli M, Bonsignori F, Galli L, de Martino M: Parental and medical knowledge and management of fever in Italian pre-school children. BMC Pediatr 2012, 13:12-97.

10. Richardson M, Lakhanpaul M; Guideline Development Group and the Technical Team: Assessment of initial management of feverish illness in children younger than 5 years: summary of NICE guidance. BMJ 2007, 334:1163-1164.

11. Sullivan JE, Farrar HC: Section on Clinical Pharmacology and Therapeutics; Committee on Drugs: fever and antipyretic use in children. Pediatrics 2011, 127:580-587.

12. Russell FM, Shann F, Curtis N, Mulholland K: Evidence on the use of paracetamol in febrile children. Bull World Health Organ 2003, 81:367-372

13. Carey JV: Literature review: should antipyretic therapies routinely be administered to patient fever? J Clin Nurs 2010, 19:2377-2393.

14. El-Radhi AS, Barry W: Do antipyretics prevent febrile convulsions? Arch Dis Child 2003, 88:641-642.

15. Eichenwald HF: Fever and antipyresis. Bull World Health Organ 2003, 81:372-374

16. Bernheim HA, Kluger MJ: Fever: effect of drug-induced antipyresis on survival. Science 1975, 188:166-168.

17. Meremikwu M, Oyo-Ita A: Physical methods for treating fever in children. Cochrane Database Syst Rev 2003, 2, CD004264.

18. Sharber J: The efficacy of tepid sponge bathing to reduce fever in young children. Am J Emerg Med 1997, 15:188-192.

19. Shang A, Huwiler-Müntener $K$, Nartey L, Jüni $P$, Dörig S, Sterne JA, Pewsner D, Egger M: Are the clinical effects of homoeopathy placebo effects? Comparative study of placebo-controlled trials of homoeopathy and allopathy. Lancet 2005, 366:726-732.

20. Schmitt BD: Fever phobia: misconceptions of parents about fevers. Am J Dis Child 1980, 134:176-181.

21. Crocetti M, Moghbeli N, Serwint J: Fever phobia revisited: have parental misconceptions about fever changed in 20 years? Pediatrics 2001, 107:1241-1246.

22. May A, Bauchner H: Fever phobia: the pediatrician's contribution. Pediatrics 1992, 90:851-854.

23. Melamud A, Suwezda A, Matamoros R, Ringuelet L: Antipyretics indication by pediatricians: internet as a tool in data collections. Arch Argent Pediat 2008, 106:404-408

24. Walsh AM, Edwards HE, Courtney MD, Wilson JE, Monaghan SJ: Paediatric fever management: continuing education for clinical nurses. Nurse Educ Today 2006, 26:71-77.

25. Demir F, Sekreter O: Knowledge, attitudes and misconceptions of primary care physicians regarding fever in children: a cross sectional study. Ital Pediatr 2012, 5:38-40.
26. Kai J: Parents and their child's fever: do as I say, not as I do? Fam Pract 1998, 15:505-506.

27. Wright AD, Liebelt EL: Alternating antipyretics for fever reduction in children: an unfounded practice passed down to parents from pediatricians. Clin Pediatr (Phila) 2007, 46:146-150.

doi:10.1186/1824-7288-39-5

Cite this article as: Bettinelli et al: Symptomatic fever management among 3 different groups of pediatricians in Northern Lombardy (Italy): results of an explorative cross-sectional survey. Italian Journal of Pediatrics 2013 39:51.

\section{Submit your next manuscript to BioMed Central and take full advantage of:}

- Convenient online submission

- Thorough peer review

- No space constraints or color figure charges

- Immediate publication on acceptance

- Inclusion in PubMed, CAS, Scopus and Google Scholar

- Research which is freely available for redistribution

Submit your manuscript at www.biomedcentral.com/submit
C) BioMed Central 